\title{
Dynamic Analysis of Integrally Geared Compressors with Varying Workloads
}

\author{
Ming Zhang, Zhinong Jiang, and Jinji Gao \\ Diagnosis and Self-Recovery Engineering Research Center, Beijing University of Chemical Technology, Beijing 100029, China \\ Correspondence should be addressed to Zhinong Jiang; jiangzhinong@263.net
}

Received 19 June 2016; Revised 22 August 2016; Accepted 20 September 2016

Academic Editor: Chao Tao

Copyright (C) 2016 Ming Zhang et al. This is an open access article distributed under the Creative Commons Attribution License, which permits unrestricted use, distribution, and reproduction in any medium, provided the original work is properly cited.

\begin{abstract}
Integrally geared compressors are characterized by compact and high efficiency machines, which are widely used in modern processing industries. As an important part of integrally geared compressors, a geared rotor-bearing system exhibits complicated dynamic behaviors. When running at rated speeds, a coupling system likely produces resonance with an adjusted workload, and a critical load phenomenon occurs. The dynamic coefficients of bearings, axial force and torque, and gear meshing stiffness vary with workload because of the interaction between rotors. In this study, a dynamic model of a geared rotor-bearing system influenced by the dynamic coefficients of bearings, axial force and torque, and gear meshing stiffness is developed. The dynamic responses of the coupling system are calculated and analyzed by using a typical five-shaft integrally geared compressor as an example. The effects of different parameters on the dynamic behaviors of the proposed system are also considered in the discussion. The geared rotor-bearing system is further investigated to examine the failure mechanism of the critical load.
\end{abstract}

\section{Introduction}

Integrally geared compressors are key components of processing industries. They are applied extensively in refineries, chemical plants, and other fields because of their compact structure, high efficiency, and wide performance. Geared rotor-bearing systems are generally operated beyond the first or second critical speed, and such systems provide secure and steady operation that contributes to the safety, stability, and long-term operation of integrally geared compressors. These systems can also be considered a set of rotor-bearing systems dynamically interacting with one another and exhibiting very complicated dynamic behaviors [1]. Therefore, accurate dynamic knowledge about geared rotor-bearing systems should be obtained.

Geared rotor-bearing systems can be efficiently modeled by finite element methods. Nelson and McVaugh [2] used a consistent matrix approach and developed a finite element model of a rotor-bearing system by considering the effects of rotatory inertia, gyroscopic moments, and axial force. Zorzi and Nelson $[3,4]$ increased the influence of internal damping and axial torque on the basis of a previous model [2]. Kahraman et al. [5] creatively utilized the finite element method to establish a model of a geared rotor-bearing system by determining the rotary inertia of a shaft element, axial force on shafts, flexibility and damping of bearings, material damping of shafts, and stiffness and damping of a gear mesh. Their work [2-5] illustrated that accurate dynamic behaviors can be obtained with finite element method.

Compared with general rotor-bearing systems, geared rotor-bearing systems are difficult to analyze. Nevertheless, geared system dynamics have been extensively investigated. Rao et al. [6] examined the coupling between bending and torsion caused by gears and considered the axial torque to determine the lateral response to torsional excitation. $\mathrm{Wu}$ and Chen [7] presented a simple approach to eliminate torsional vibration in a gear-branched system via finite element method. Choi et al. [8] and Lee et al. [9] evaluated the dynamic characteristics of coupled lateral, torsional, and axial vibration in a helical geared system. Kubur et al. [10] and Lee and Ha [11] also analyzed the unbalance response of a geared rotor-bearing system. A dynamic model of geared rotor-bearing systems has also been developed on the basis of previous studies and relevant factors, including geometric eccentricity, transmission error, and some unavoidable defects [12-14]. The nonlinear dynamic characteristics of 
geared rotor-bearing systems have also been widely explored [15-17].

The complicated dynamic behaviors, including linear and nonlinear characteristics, of geared rotor-bearing systems have been extensively investigated. However, the dynamic characteristics of geared rotor-bearing systems considering varying workload have been rarely explored. Integrally geared compressors likely cross numerous critical speeds during compressor start up. When running at rated speeds, integrally geared compressors produce resonance with adjusted workload, and a critical load phenomenon occurs. Gao [18] discovered and successfully resolved a DH integrally geared compressor failure caused by critical load. Therefore, our study mainly aims to examine the effect of different workloads on the dynamic characteristics of a geared rotorbearing system and to investigate the failure mechanism of the critical load.

In this paper, a general finite element approach of geared rotor-bearing system is presented in Section 2. The dynamic model of geared rotor-bearing system covers the effects of bearing flexibility and damping, axial force and torque, and gear meshing. A five-shaft integrally geared compressor is modeled and discussed in Section 3. The bearing dynamic coefficients, axial force and torque, and gear meshing stiffness are changed as workload varies because of the interaction in the geared rotor-bearing system. The dynamic responses of the system under different parameters are also analyzed. Our results indicate that the bearing dynamic coefficients and gear meshing stiffness significantly influence the responses of the geared rotor-bearing system, but the axial force and torque slightly influence such responses. The resonance peaks and their phase of the critical load are obtained from the dynamic responses affected by the bearing dynamic coefficients, axial force and torque, and gear meshing stiffness.

\section{Dynamic Modeling for Geared Rotor-Bearing System}

In this section, the FE dynamic equation of the geared rotorbearing system influenced by the flexibility and damping of bearings, axial force, axial torque, and gear meshing is presented. The assembly method of the coupling system equation is also investigated.

2.1. Rotor-Bearing System Dynamic Equation. The coordinates defining bending as the two planes are shown in Figure 1. The local coordinate of the finite rotor element is $q^{e}=\left[u_{i}, v_{i}, \theta_{i}, \psi_{i}, u_{j}, v_{j}, \theta_{j}, \psi_{j}\right]$. The dynamic equation of the finite rotor element is as follows:

$$
\left(M_{T}^{e}+M_{R}^{e}\right) \ddot{q}^{e}-\Omega G^{e} \dot{q}^{e}+K_{B}^{e} q^{e}=Q^{e},
$$

where $M_{T}^{e}$ and $M_{R}^{e}$ are the element mass matrices; $K_{B}^{e}$ is the element bending stiffness matrix; $G^{e}$ is the element gyroscopic matrix; $\Omega$ is the spin speed; $Q^{e}$ is the external force vector of the rotor element. The matrices in (1) are defined in Appendix A.

The coupling of the input shaft, the impellers of output shafts, and the gear of the middle shaft are regarded as a rigid disk (with gyroscopic effect). When the local coordinates are defined as $q^{d}=[u, v, \theta, \psi]$, the dynamic equation of the rigid disk is as follows:

$$
M^{d} \ddot{q}^{d}-\Omega G^{d} \dot{q}^{d}=Q^{d}
$$

where $\Omega$ is the spin speed; $Q^{d}$ is the external force vector of the rigid discs; $M^{d}$ and $G^{d}$ are the mass matrix and gyroscopic matrix for the disk, respectively, and defined as follows:

$$
\begin{aligned}
M^{d} & =\left[\begin{array}{cccc}
m_{d} & 0 & 0 & 0 \\
0 & m_{d} & 0 & 0 \\
0 & 0 & I_{d} & 0 \\
0 & 0 & 0 & I_{d}
\end{array}\right], \\
G^{d} & =\left[\begin{array}{cccc}
0 & 0 & 0 & 0 \\
0 & 0 & 0 & 0 \\
0 & 0 & 0 & I_{p} \\
0 & 0 & -I_{p} & 0
\end{array}\right] .
\end{aligned}
$$

The bearings utilized in this paper are limited to those which obey the governing equations of the form

$$
C^{b} \dot{q}^{b}+K^{b} q^{b}=Q^{b}
$$

in the local coordinates, where $Q^{b}$ is the bearing external force vector; $K^{b}=\left[\begin{array}{ll}k_{u u} & k_{u v} \\ k_{v u} & k_{v v}\end{array}\right]$ is the stiffness matrix of bearing; and $C^{b}=\left[\begin{array}{lll}c_{u u} & c_{u v} \\ c_{v u} & c_{v v}\end{array}\right]$ is the damping matrix of bearing.

2.2. Incremental Stiffness due to Axial Force and Axial Torque. In the integrally geared compressor, the mechanical power developed by the turbine is transmitted through the input shaft to the output shaft impellers where gas is pressurized. The purpose of the geared rotor-bearing system usually depends fundamentally on this transmission of torque. Each shaft of the compressor carries some torque about the axis of rotation. The helical gear meshing is generally used for integrally geared compressors to ensure the stability of transmission. The mechanical power of integrally geared compressors contributes to not only the axial torque but also the axial force because of the effect of helical gear meshing. The axial force along the undeformed axis of the rotor occurs in each shaft of the coupling system. Nelson and McVaugh [2] developed the equation of motion for a rotating finite shaft element, including the effect of axial force. The result is a stiffening effect if the shaft is in tension or a softening effect 

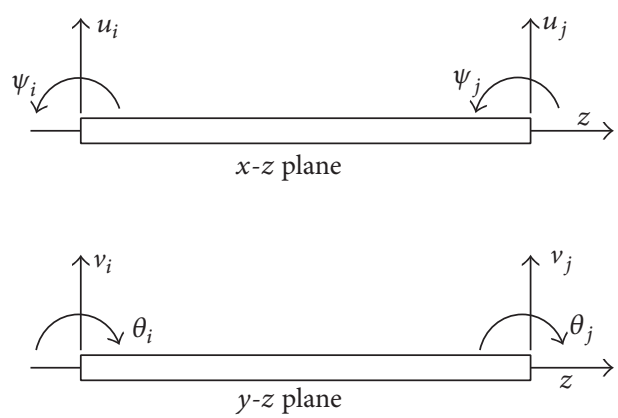

Figure 1: The local coordinates in the bending planes.

if the force is compressive. The lateral motion of an EulerBernoulli beam element of the axial force is as follows:

$$
=\frac{F_{a}}{30 l_{e}}\left[\begin{array}{cccccccc}
36 & K_{A}^{e} \\
0 & 36 & & \multicolumn{5}{c}{\text { sym }} \\
0 & -3 l_{e} & 4 l_{e}^{2} & & & & \\
3 l_{e} & 0 & 0 & 4 l_{e}^{2} & & & & \\
-36 & 0 & 0 & -3 l_{e} & 36 & & & \\
0 & -36 & 3 l_{e} & 0 & 0 & 36 & & \\
0 & -3 l_{e} & -l_{e}^{2} & 0 & 0 & 3 l_{e} & 4 l_{e}^{2} & \\
3 l & 0 & 0 & -l_{e}^{2} & -3 l_{e} & 0 & 0 & 4 l_{e}
\end{array}\right] \text {, }
$$

where $F_{a}$ is the axial tensile force within the element.

The axial torque within a shaft may affect the lateral behavior, which is similar to the effect caused by the axial force in a shaft. Relatively few papers or texts on rotor dynamics consider this coupling, although Zorzi and Nelson [4] derive the contribution to the stiffness for the lateral motion of an Euler-Bernoulli beam element, as follows:

$$
K_{T}^{e}=\tau_{e} \tau_{e}\left[\begin{array}{cccccccc}
0 & 0 & 2 & 0 & 0 & 0 & -2 & 0 \\
0 & 0 & 0 & 2 & 0 & 0 & 0 & -2 \\
2 & 0 & 0 & -l_{e} & -2 & 0 & 0 & l_{e} \\
0 & 2 & l_{e} & 0 & 0 & -2 & -l_{e} & 0 \\
0 & 0 & -2 & 0 & 0 & 0 & 2 & 0 \\
0 & 0 & 0 & -2 & 0 & 0 & 0 & 2 \\
-2 & 0 & 0 & -l_{e} & 2 & 0 & 0 & l_{e} \\
0 & -2 & l_{e} & 0 & 0 & 2 & -l_{e} & 0
\end{array}\right],
$$

where $\tau_{e}$ is the transmitted torque within the element.

2.3. Gear Meshing Stiffness. Connecting the shafts through the helical gear in the geared rotor-bearing system often causes couple vibration. Helical gear meshing stiffness is investigated on the basis of a previous study [6]. The relationship between contact force and displacements of a gear pair is determined by representing the teeth in contact with an equivalent stiffness along the pressure line, as shown in Figure 2. The rotations $\theta$ and $\psi$ are small in a gear pair; as such, we can disregard these terms. Along the pressure line, gear $_{i}$ moves as follows:

$$
x_{g}^{i}=u_{i} \sin \alpha \cos \beta+v_{i} \cos \alpha \cos \beta+r_{i} \phi_{i} \cos \beta
$$

and gear $_{j}$ moves as follows:

$$
x_{g}^{j}=u_{j} \sin \alpha \cos \beta+v_{j} \cos \alpha \cos \beta+r_{j} \phi_{j} \cos \beta,
$$

where $r_{i}$ and $r_{j}$ are the base circle radii of the two gears; $\alpha$ is the pressure angle; $\beta$ is helix angle; $\phi_{i}$ and $\phi_{j}$ are the torsional displacements of the gears about the $z$-axil; $u_{i}$ and $u_{j}$ are the displacement of gear ${ }_{i}$ and gear ${ }_{j}$ in the $x$ direction; $v_{i}$ and $v_{j}$ are the displacement of gear ${ }_{i}$ and gear ${ }_{j}$ in the $y$ direction.

Therefore, the relative displacement at the gear mesh is as follows:

$$
\begin{aligned}
x_{g}= & \left(u_{j}-u_{i}\right) \sin \alpha \cos \beta+\left(v_{j}-v_{i}\right) \cos \alpha \cos \beta \\
& -\left(r_{i} \phi_{i}+r_{j} \phi_{j}\right) \cos \beta=N_{g} q_{g},
\end{aligned}
$$

where

$$
\begin{aligned}
N_{g} & =\left[\begin{array}{llllllllllll}
-\sin \alpha \cos \beta & -\cos \alpha \sin \beta & 0 & 0 & \sin \alpha \cos \beta & \cos \alpha \cos \beta & 0 & 0 & -r_{i} \cos \beta & -r_{j} \cos \beta
\end{array}\right], \\
q_{g} & =\left[\begin{array}{lllllllll}
u_{i} & v_{i} & \theta_{i} & \psi_{i} & u_{j} & v_{j} & \theta_{j} & \psi_{j} & \phi_{i}
\end{array}\right] .
\end{aligned}
$$

The strain energy within the gear mesh is as follows:

$$
U_{g}=\frac{1}{2} k_{g} x_{g}^{2}=\frac{1}{2} k_{g} q_{g}^{T} N_{g}^{T} N_{g} q_{g}
$$

where $k_{g}$ is the gear mesh stiffness. Thus, the stiffness matrix of gear mesh is as follows:

$$
K_{g}=k_{g} N_{g}^{T} N_{g}
$$

The matrix of $K_{g}$ is defined in Appendix B. 
2.4. The Dynamic Equation of Geared Rotor-Bearing System. Equations (1), (2), (5), (6), and (12) can be combined for the geared coupled system. The dynamic equation of geared rotor-bearing system is as follows:

$$
\begin{aligned}
M^{s} \ddot{q} & +\left(C_{b}^{s}-\Omega G^{s}\right) \dot{q}^{s} \\
& +\left(K_{B}^{s}+K_{b}^{s}+K_{g}^{s}-K_{A}^{s}-K_{T}^{s}\right) q^{s}=Q^{s},
\end{aligned}
$$

where $M^{s}$ is the mass matrix; $C_{b}^{s}$ is the damping matrix of bearing; $\Omega$ is the spin speed; $G^{s}$ is the gyroscopic matrix; $K_{B}^{s}, K_{b}^{s}, K_{g}^{s}, K_{A}^{s}$, and $K_{T}^{s}$ are the stiffness matrix of the rotor, bearing, gear, axial load, and axial torque, respectively; $Q^{S}$ is the external force vector; $q^{s}$ is the displacement vector which is defined as follows:

$$
\begin{aligned}
& q^{s}=\left[u_{1}, v_{1}, \theta_{1}, \psi_{1}, \phi_{1}, u_{2}, v_{2}, \theta_{2}, \psi_{2}, \phi_{2}, \ldots, u_{n}, v_{n}, \theta_{n}, \psi_{n},\right. \\
& \left.\phi_{n}\right] .
\end{aligned}
$$

2.5. Assembly of the Coupling System Equation. In order to construct an entire geared rotor-bearing system equation, an assembly method of the single rotor finite element (FE) models of the shafts, bearings and disks, and the gear pair FE models is stated as follows. The single rotor FE model assembly method is detailed in the book by Vollan and Komzsik [19]. Figure 3 shows such a simple geared system which is used as an example to illustrate the assembly method of the entire system equation. The nodes on each gear are connected by a stiffness matrix. In a geared system, the element matrices are inserted into the system matrices in the positions determined by the positions of the local element coordinates in the global vector. This is demonstrated diagrammatically in Figure 4 for the example of Figure 3 in which the nonzero degrees of freedom are shaded. The blocks in shades of light gray and dark gray denote the positions corresponding to Rotor 1 and Rotor 2, respectively. The black squares denote the stiffness matrix for the connection of the gear meshing, which is split into four blocks that slot into the position of Node 3 and Node 6 in the entire system equation. Then, the entire assembled equation of a geared system is implemented as shown in Figure 4.

2.6. Validation of Dynamic Model. A $600 \mathrm{~kW}$ turbo-chiller rotor-bearing system with a bull-pinion speed-increasing gear is applied to validate the correctness of the model proposed in this paper. The dynamic model of the turbochiller rotor-bearing system is shown in Figure 5, and the system parameters are based on a previous study [9]. With a test unbalance of $U=19.7 \mathrm{~g} \cdot \mathrm{mm}$ attached to the impeller, the coupled unbalance responses at the driver shaft calculated by the proposed method are shown in Figure 6. Our results (Figure 6) are consistent with those described in a previous study [9].

\section{Results and Discussions}

Applying the proposed method, we perform an unbalance response analysis with a five-shaft geared rotor-bearing system of an integrally geared compressor (Figure 7). The input

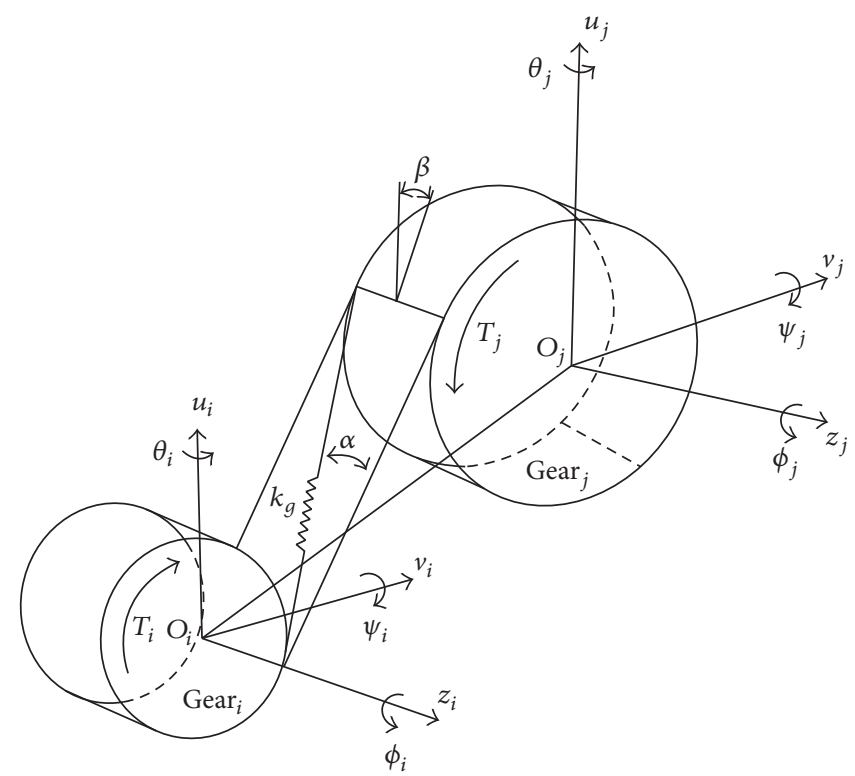

FIGURE 2: Gear meshing system model.

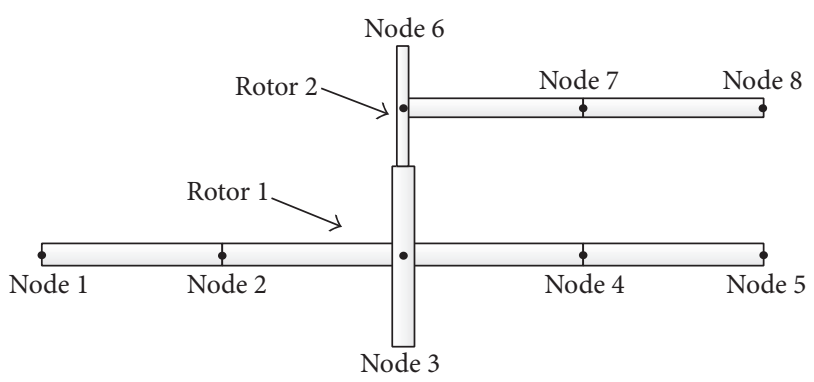

FIGURE 3: Rotors coupled by a gear.

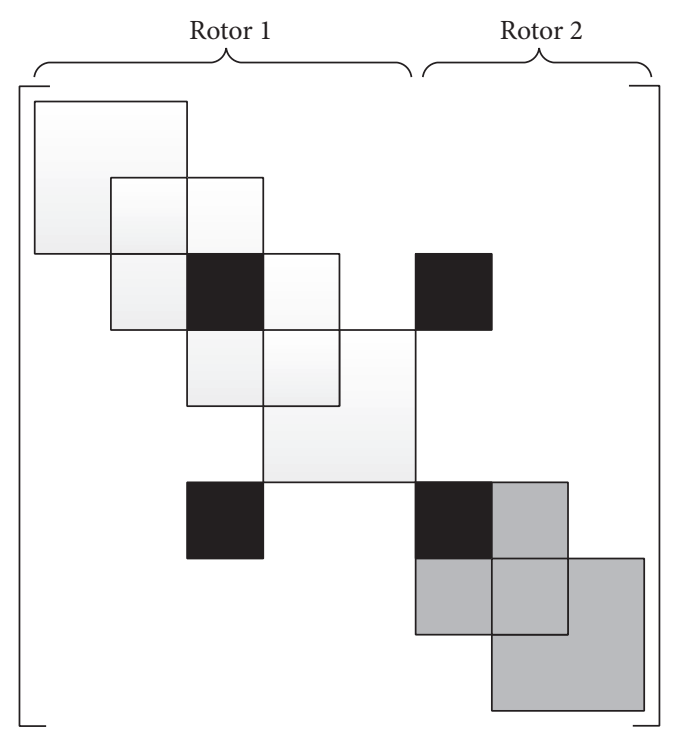

FIGURE 4: Structure of the entire assembled equation for a geared system. 


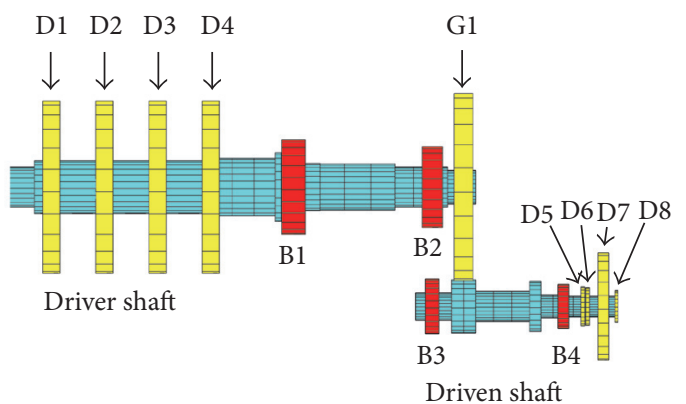

FIgURe 5: Dynamic model of the turbo-chiller rotor-bearing system in [9].

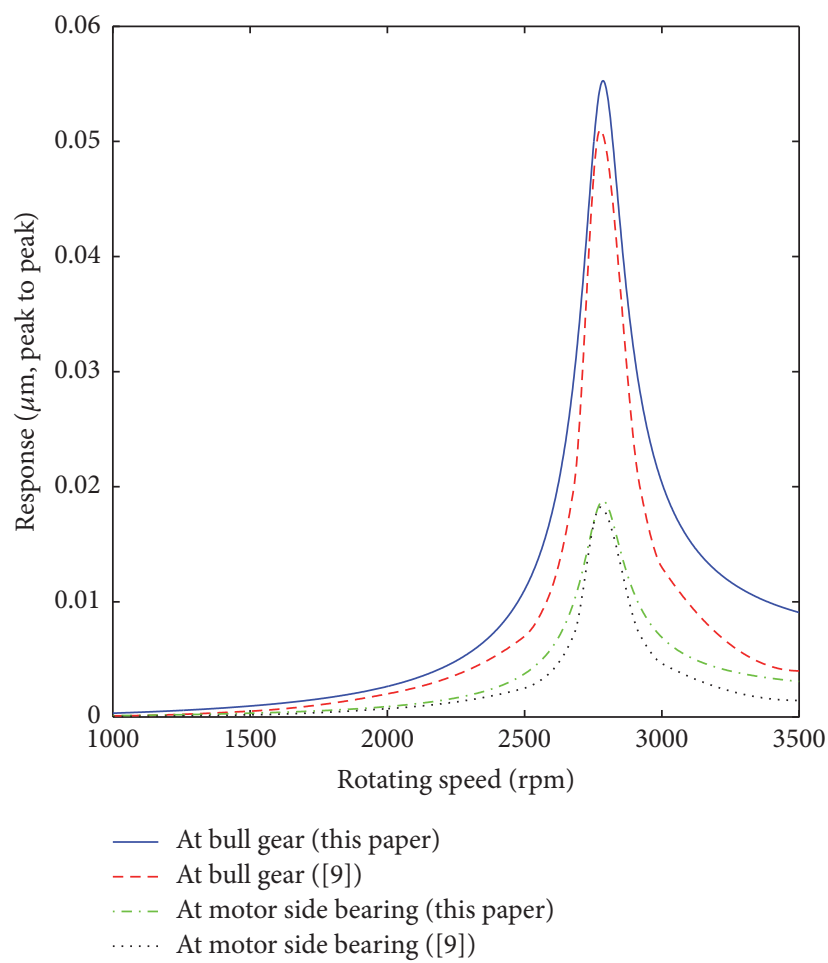

FIGURE 6: Unbalance responses comparing with [9].

shaft and three output shafts (O1, O2, and O3) are coupled together by the transmission gear of the middle shaft in this coupling system. Each shaft is a general rotor-bearing system supported by oil film bearings. The impellers are fixed on the output shafts to compress the gas.

In the five-shaft geared rotor-bearing system, each shaft has the same material properties. Young's modulus of shaft is $E=2.059 \times 10^{11} \mathrm{~N} / \mathrm{m}^{2}$; shear modulus of shaft is $G=$ $7.919 \times 10^{10} \mathrm{~N} / \mathrm{m}^{2}$; the density of the shaft material is $\rho=$ $7850 \mathrm{~kg} / \mathrm{m}^{3}$; and the Poisson ratio of the shaft is $v=0.3$. Table 1 lists the physical parameters of five gears. Five shafts unbalance and location calculated by ISO-1940-1:2003 [20] is listed in Table 2 and tilting pad bearing parameters of five shafts are presented in the Table 3. All the other data for the system are shown in the Figure 7.
TABLE 1: Physical parameters of five gears.

\begin{tabular}{lccccc}
\hline & Input & Middle & Output 1 & Output 2 & Output 3 \\
\hline Power $(\mathrm{kW})$ & 15600 & 15600 & 4600 & 6500 & 4500 \\
Pitch diameter (mm) & 719 & 1984 & 264 & 221 & 141 \\
Tooth width (mm) & 224 & 152 & 224 & 224 & 224 \\
Location & $40^{\circ}$ & $0^{\circ}$ & $270^{\circ}$ & $90^{\circ}$ & $180^{\circ}$ \\
Normal modulus & & & 5 & & \\
Pressure angle & & & $20^{\circ}$ & & \\
Helix angle & & & $12^{\circ}$ & & \\
\hline
\end{tabular}

TABLE 2: Five shafts unbalance and location.

\begin{tabular}{|c|c|c|c|c|c|c|c|}
\hline & Input & Middle & Output 1 & \multicolumn{2}{|c|}{ Output 2} & \multicolumn{2}{|c|}{ Output 3} \\
\hline Mass (kg) & 1098.69 & 4299.15 & 383.29 & 35 & 9.03 & & .26 \\
\hline $\begin{array}{l}\text { Unbalance } \\
(\mathrm{g} \mathrm{mm})\end{array}$ & 4395 & 64487 & 958 & 359 & 359 & 72 & 72 \\
\hline $\begin{array}{l}\text { Location } \\
\text { node }\end{array}$ & 2 & 38 & 88 & 89 & 133 & 144 & 174 \\
\hline
\end{tabular}

TABLE 3: Bearing parameters of five shafts.

\begin{tabular}{lccccc}
\hline & Input & Middle & Output 1 & Output 2 & Output 3 \\
\hline $\begin{array}{l}\text { Bearing } \\
\text { diameter } \\
(\mathrm{mm})\end{array}$ & 180 & 250 & 100 & 110 & 80 \\
$\begin{array}{l}\text { Bearing } \\
\text { width (mm) }\end{array}$ & 176 & 150 & 90 & 98 & 72 \\
$\begin{array}{l}\text { Bearing } \\
\text { radial } \\
\text { clearance } \\
\text { (mm) }\end{array}$ & 0.06 & 0.05 & 0.09 & 0.116 & 0.096 \\
$\begin{array}{l}\text { Pad number } \\
\text { Rated speed } \\
\text { (rpm) }\end{array}$ & 4 & 2 & 5 & 5 & 5 \\
\hline
\end{tabular}

When running at the rated speeds, integrally geared compressor needs to adjust the load according to the practical requirements. Since the interaction of the geared rotorbearing system, the workload is associated with the bearing dynamic coefficients, axial force and torque on the shaft, and gear meshing stiffness. In the integrally geared compressor, the input shaft and the middle shaft bearing the workload are generated by all the output shafts and usually run below the first critical speed. Therefore, resonance is difficult to produce with the workload adjustment when the input shaft and middle shaft are running at the rated speed. On the contrary, output shafts have rated speeds higher than the critical speed. When running at the rated speeds, they may produce resonance with the workload adjustment, and the critical load phenomenon occurs. This vibration problem is investigated by linear unbalance response analysis of the geared rotor-bearing system with varying workloads.

In order to construct the geared rotor-bearing system model, we utilize the meshing stiffness of the gear pair to connect the five single rotor-bearing systems. The motion of the gear pair is determined by the gear mesh stiffness 


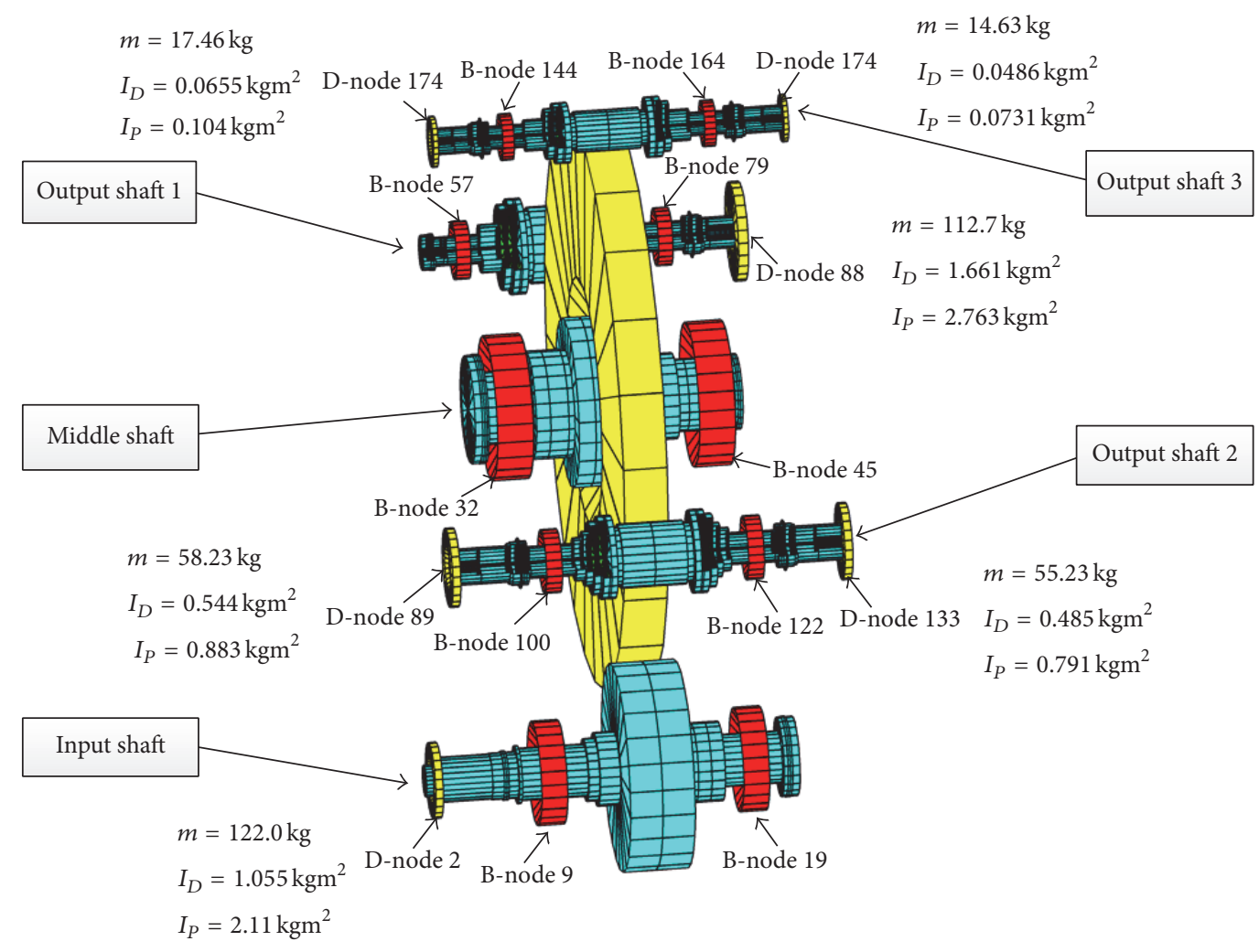

FIGURE 7: Five-shaft geared rotor-bearing system of integrally geared compressors.

(see Section 2.3). Using the proposed model to calculate the linear unbalance response of the geared rotor-bearing system, the resonance speed of the three output shafts under the interaction of the gears can be obtained. The vibration problem of geared rotor-bearing system is discussed and analyzed in detail based on the three-dimensional map of linear unbalance response with varying workloads.

In this section, we discussed the relationship between the workload and the bearing dynamic coefficients, axial force and torque, and gear meshing stiffness, obtained, respectively, linear unbalance response under the effect of bearing dynamic coefficients, axial force and torque, and gear meshing stiffness by using the dynamic modeling method in Section 2, and analyzed the influence of different factors on the critical speed in the process of workload variation. Then, by analyzing the unbalance response under the influence of all factors, the critical load of the geared rotor-bearing system is verified.

\subsection{Unbalance Response Analysis of the Geared Rotor-Bearing} System considering Varying Workload. According to the force analysis of typical helical gears (Figure 8), we can obtain

$$
\begin{aligned}
& F_{t}=\frac{2 T}{d}, \\
& F_{r}=\frac{F_{t} \tan \alpha}{\cos \beta}, \\
& F_{a}=F_{t} \tan \beta,
\end{aligned}
$$

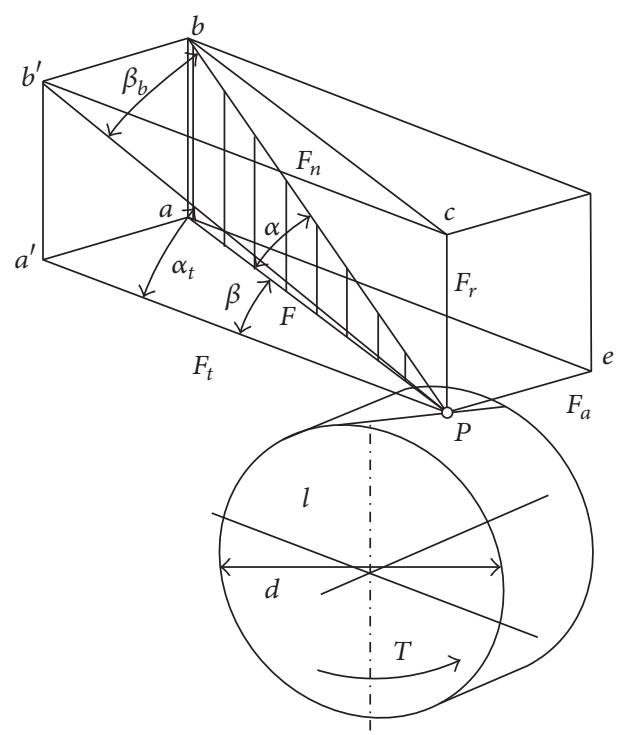

FIGURE 8: Force analysis of helical gears.

where $F_{t}$ is the circumferential force; $F_{r}$ is the radial force; $F_{a}$ is the axial force; $T$ is the torque; $d$ is the pitch diameter; $\alpha$ is the pressure angle; $\beta$ is the helix angle.

When running at the rated speed, the change of the workload has directly led to torque variant based on the formula which is

$$
T=\frac{9550 P}{n}
$$




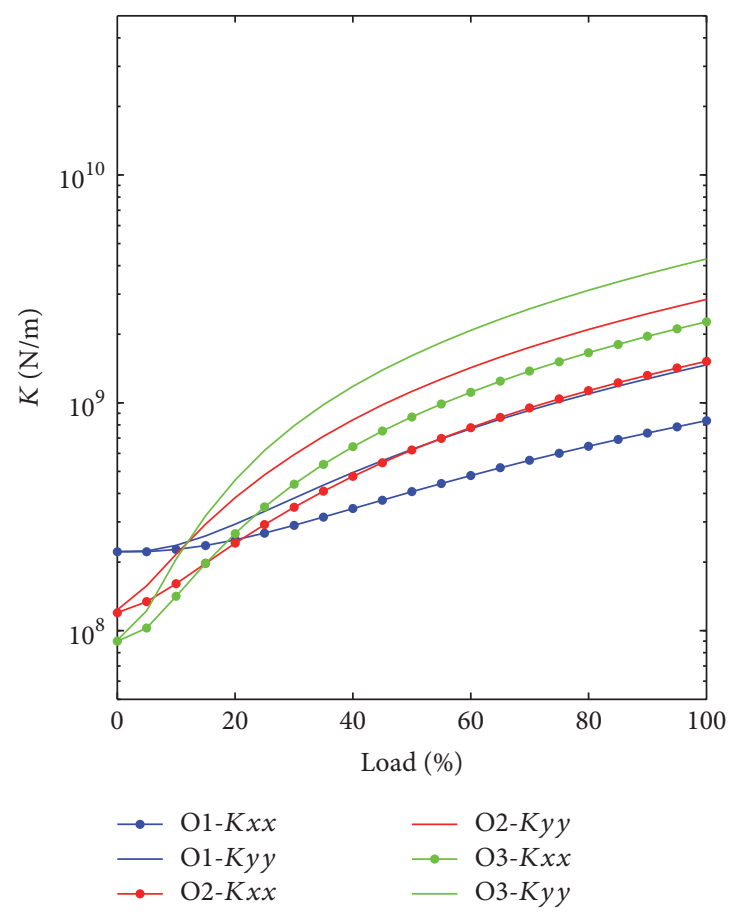

(a)

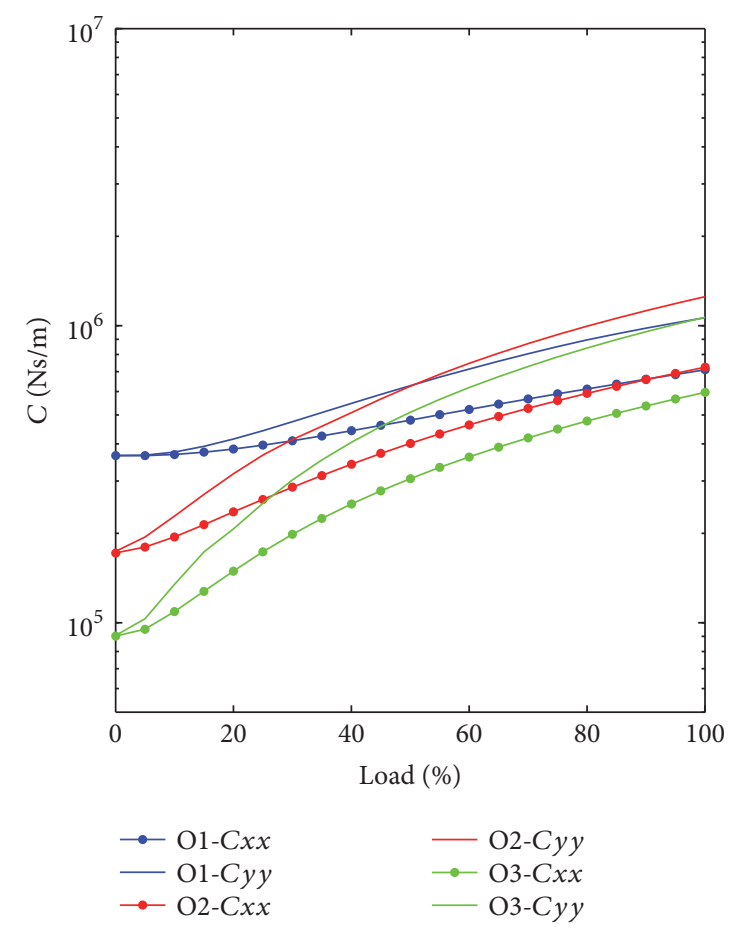

(b)

FIGURE 9: Effect of increasing workload on the tilting pad bearings of three output shafts, (a) stiffness coefficients; (b) damping coefficients.

where $T$ is the torque; $P$ is the workload; $n$ is the rated speed. The circumferential force $F_{t}$ is related to the gear meshing stiffness detailed in ISO-6636-1:2006 [21] and the radial force $F_{r}$ acting directly on the shaft, which will affect the bearing dynamic coefficients determined primarily bearing endured force. In a word, we can conclude that the bearing dynamic coefficients, axial force and torque, and gear meshing stiffness change with the workload variation.

3.1.1. Effect of Bearing Dynamic Coefficients. In this paper, the unbalance response is linearly analyzed to determine the resonance speed. The existing program Dyrobes-BePerf has been developed to analyze the dynamic performance of tilting pad hydrodynamic journal bearings based on the FE Method. The linear bearing stiffness coefficients and damping coefficients can be calculated by this program. Figure 9 shows the effect of increasing workload on the bearings of the output shafts. As the workload increases, the stiffness coefficients and damping coefficients of each shaft bearing in $x$-direction and $y$-direction are increasing. To demonstrate the effect of bearing dynamic coefficients, unbalance responses of three output shafts only considering the increasing stiffness coefficients and damping coefficients are presented in Figure 10. The critical speed of three output shafts is markedly increased with the increase of the dynamic coefficients of the bearings. The low order critical speed is mainly affected from the results of the calculation.

3.1.2. Effect of the Axial Force and Torque. Figure 11 shows the effect of increasing workload on the three output shafts. The output shafts will not be subjected to axial force and torque without the workload based on the above formula of gear endured force. The dynamic characteristics of the output shafts are affected when the workload increases the axial force and torque of the output shafts. Figure 12 shows the unbalance responses of three output shafts considering the axial force and torque of different workloads. The critical speeds of the output shafts are slightly reduced as workload increases.

3.1.3. Effect of the Gear Meshing Stiffness. In ISO-6636-1:2006 [21], the gear meshing stiffness is mainly affected by the specific workload during the operation of the gear coupling system and the calculation formula of gear meshing stiffness is given. Based on the formula, the gear meshing stiffness of three output shafts under different workload is calculated. The results are shown in Figure 13. The unbalance responses of three output shafts are plotted (Figure 14) to investigate the effect of gear meshing stiffness on output shafts. As the gear meshing stiffness increases, the lower-order critical speed increases slightly and the higher-order critical speed increases obviously.

The dynamic performance of the three output shafts can be influenced by the bearing dynamic coefficients, the axial force and torque, and the gear meshing stiffness. The critical speeds of the output shafts significantly change with the bearing dynamic coefficients and gear meshing stiffness varies. These changes are slightly affected by axial force and torque variation.

3.2. Critical Load Analysis of the Geared Rotor-Bearing System. Figure 15 shows the unbalance response of three output shafts considering all the influencing factors under the varying 


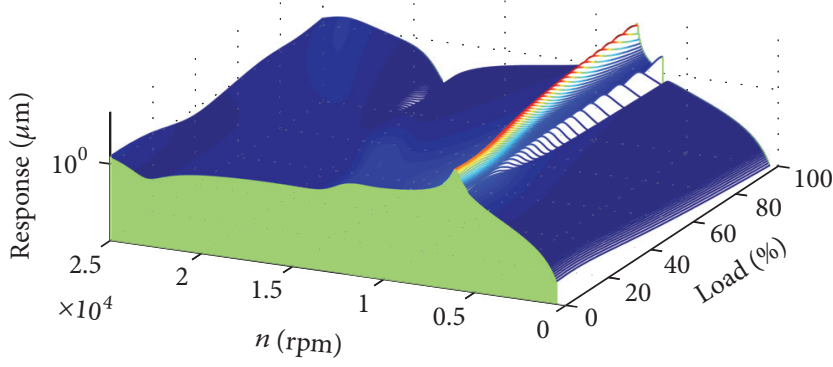

(a)

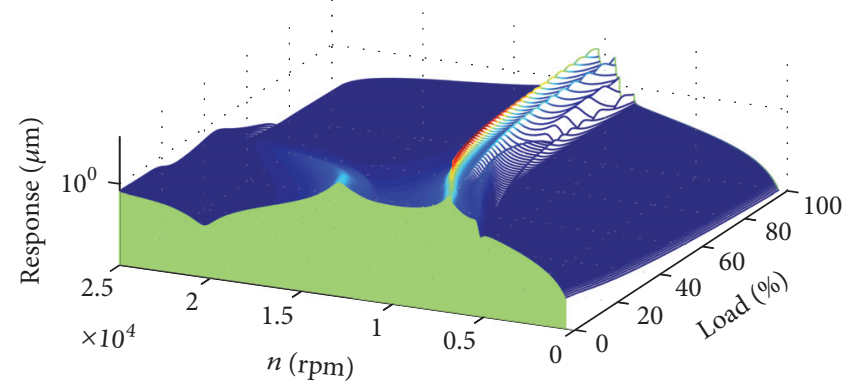

(b)

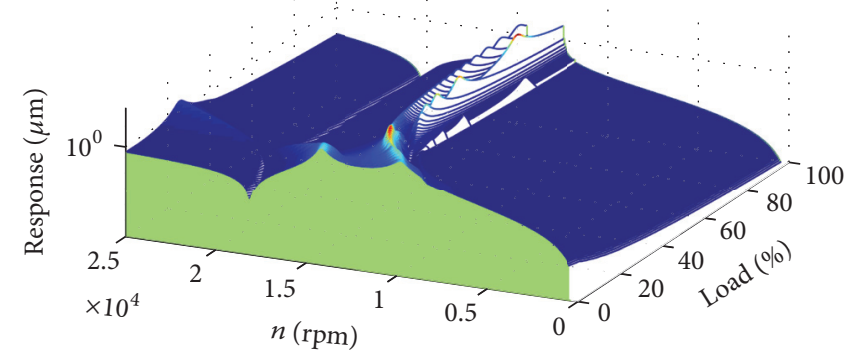

(c)

FIGURE 10: Unbalance response of three output shafts only considering dynamic coefficients under varying workload, (a) output shaft 1; (b) output shaft 2; (c) output shaft 3.

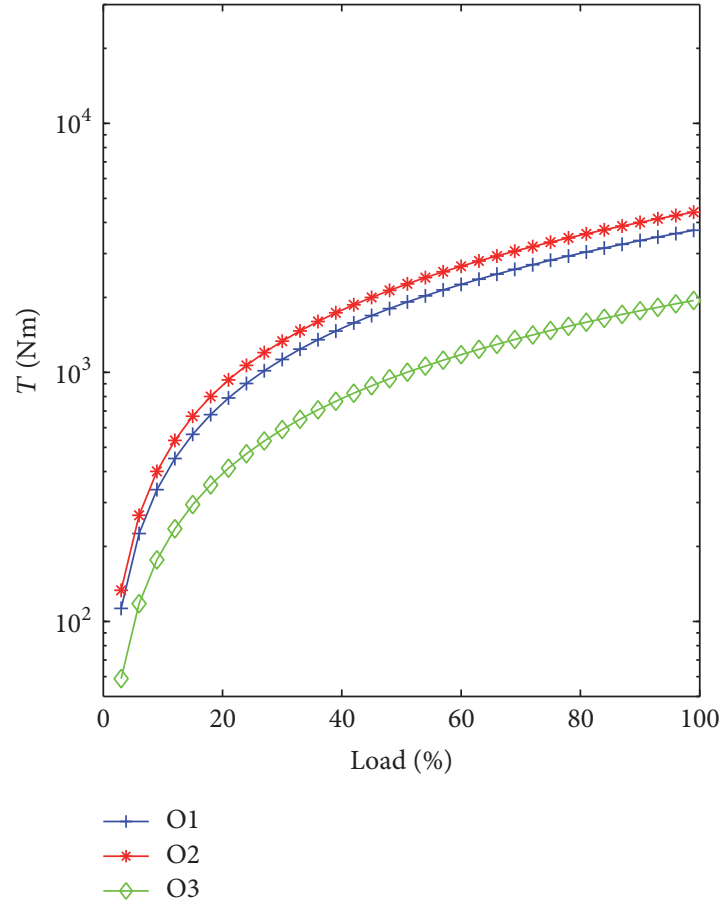

(a)

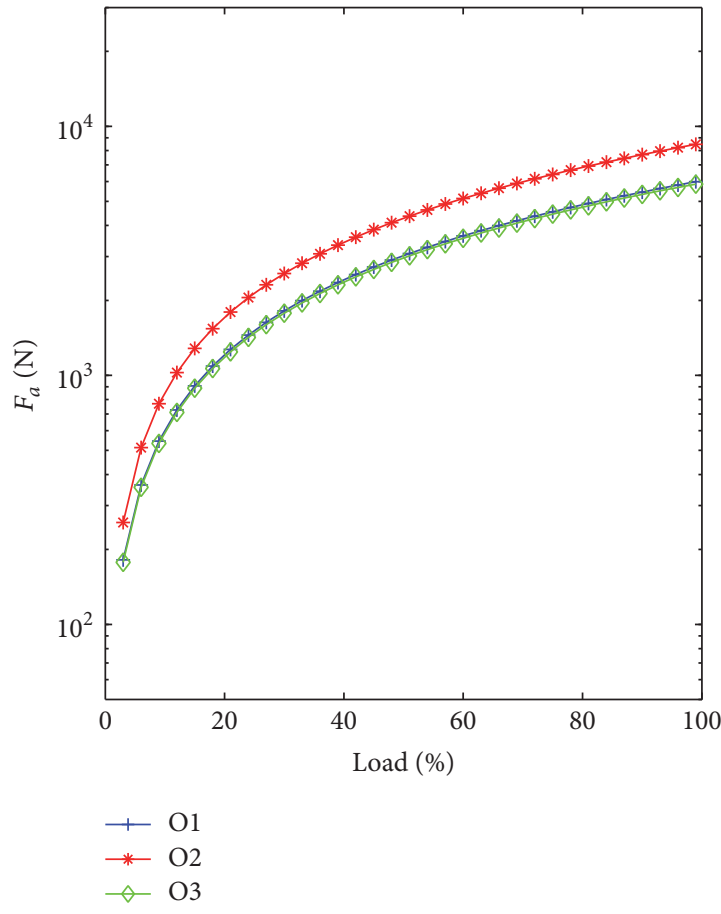

(b)

FIGURE 11: Effect of increasing workload on the three output shafts, (a) axial torque; (b) axial force.

workload. The increase of the workload results in the increase of the critical speed of output shafts. The results illustrate that the rated speed below the first critical speed will be far away from the critical speed with the critical speed increased. Therefore, the critical load unlikely occurs when the rated speed of each shaft is below the first critical speed. Conversely, output shafts are generally running above the critical speed in the integrally geared compressor, and the 


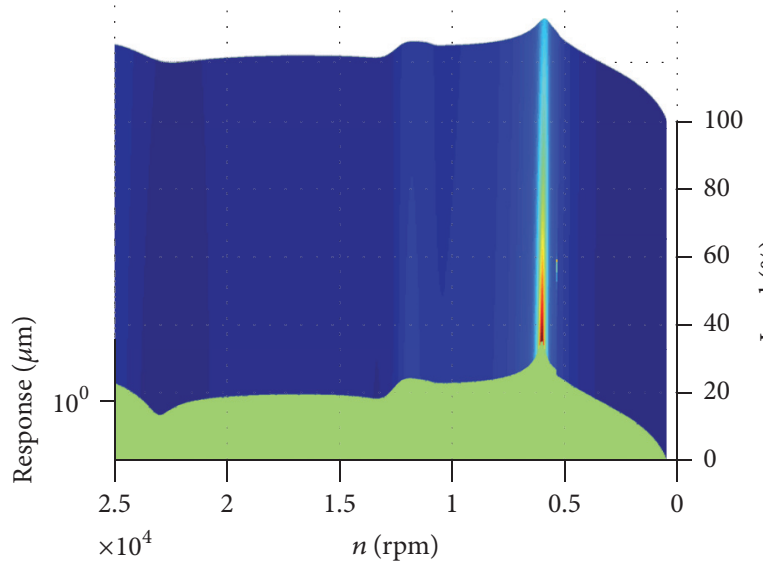

(a)

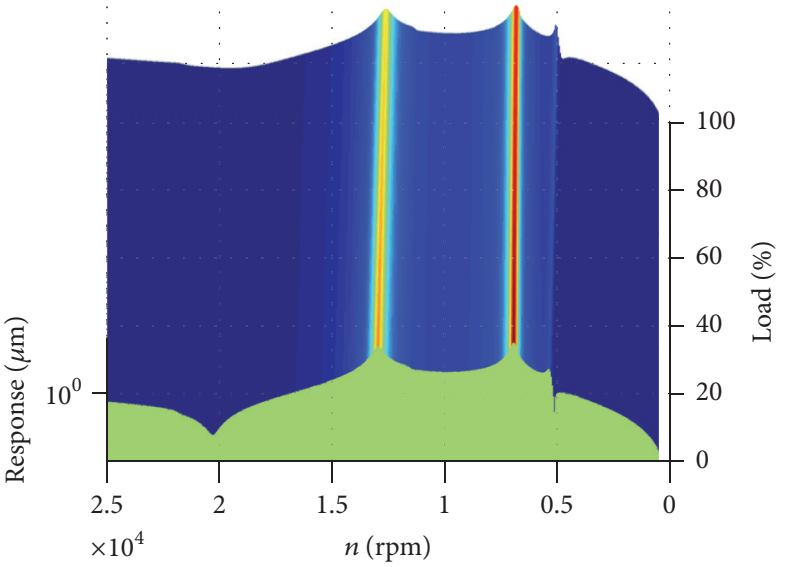

(b)

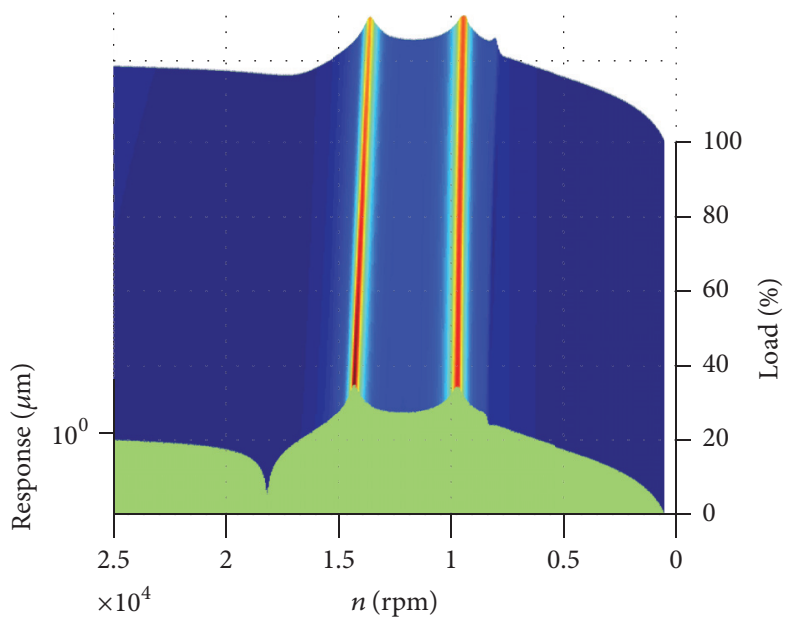

(c)

FIGURE 12: Unbalance response of three output shafts only considering axial torque and axial force under varying workload, (a) output shaft 1 ; (b) output shaft 2; (c) output shaft 3 .

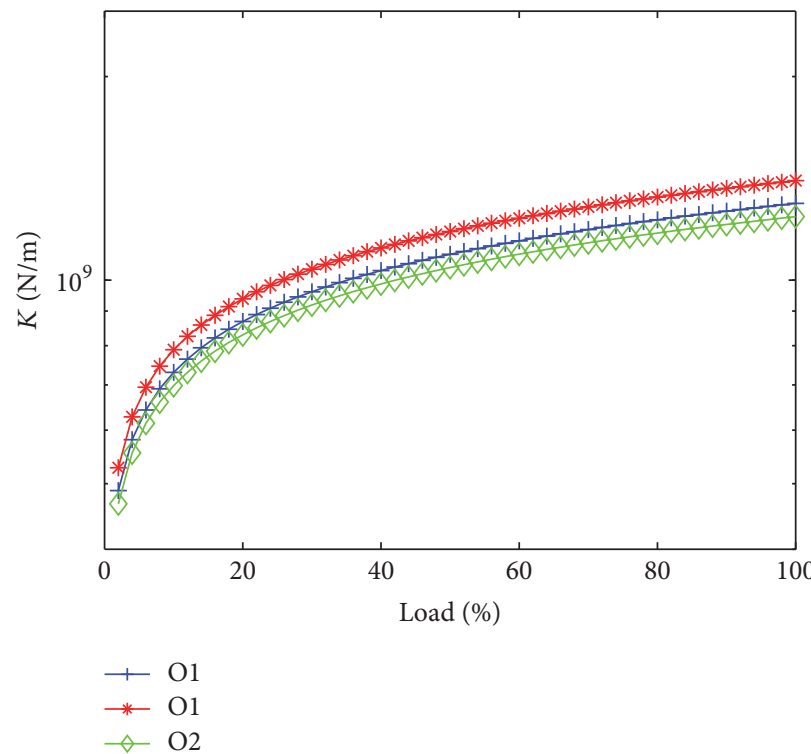

FIGURE 13: Effect of increasing workload on the gear meshing stiffness of three output shafts. 


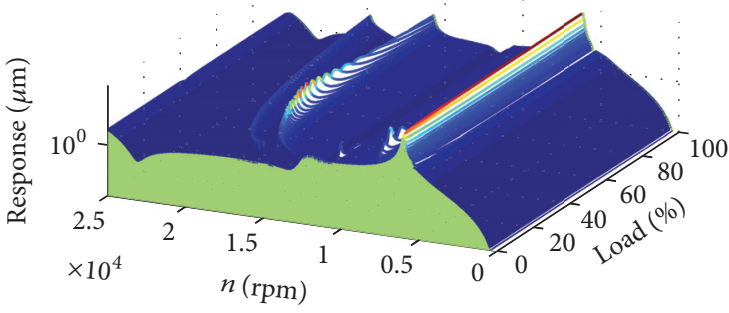

(a)

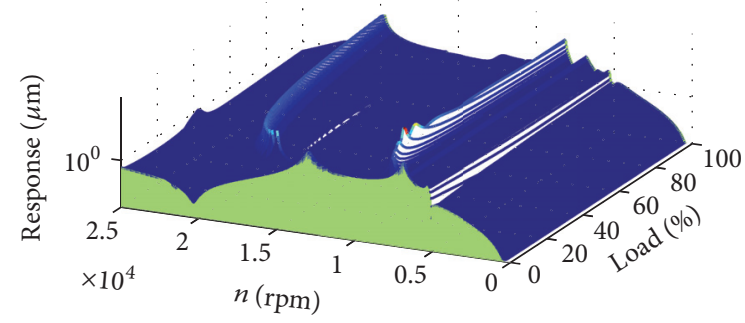

(b)

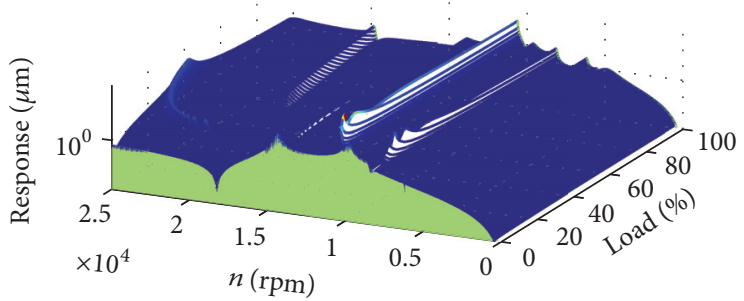

(c)

FIGURE 14: Unbalance response of three output shafts only considering gear meshing stiffness under varying workload, (a) output shaft 1, (b) output shaft 2, and (c) output shaft 3 .

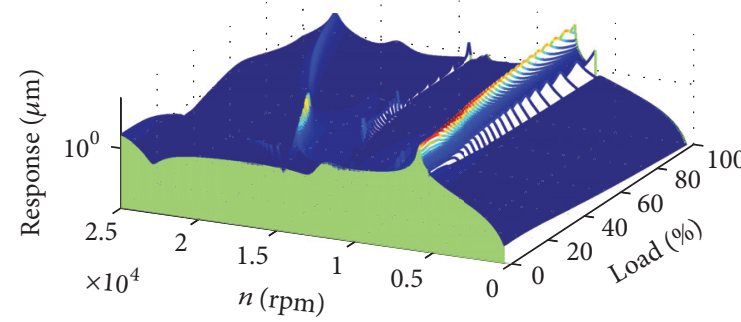

(a)

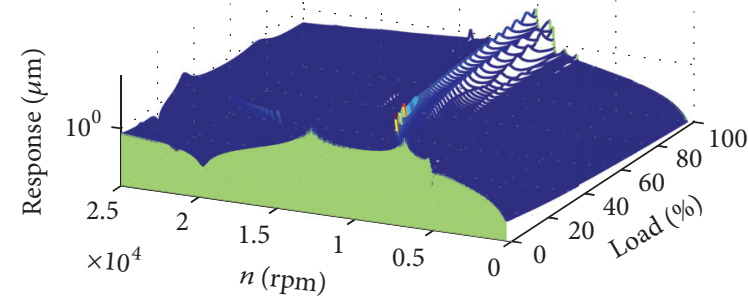

(b)

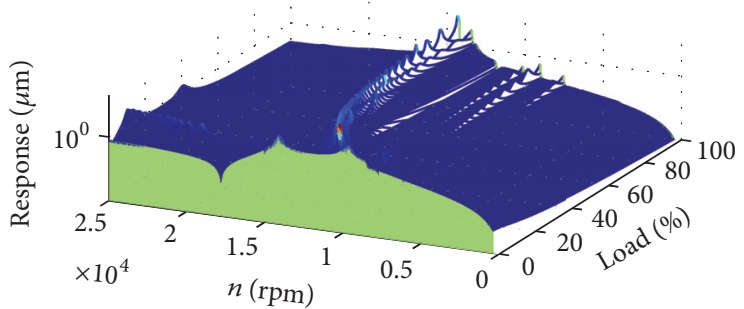

(c)

FIGURE 15: Unbalance response of three output shafts considering all the influence factors under the varying workload, (a) output shaft 1; (b) output shaft 2; (c) output shaft 3.

critical speed can be adjusted to the rated speed of the output shaft by increasing the workload. Therefore, the resonance may occur under the influence of the workload when the output shafts are running at the rated speeds. Figure 16 illustrates the response amplitude and phase of the output shafts under varying workload. A slight resonance peak with a slight phase change is observed in Figure 16(a). When the workload is close to $75 \%$, the resonance peak and its phase are obviously changed in Figure 16(b). Figure 16(c) displays that two obvious resonance peaks and their phases change significantly when the loads are close to $3 \%$ and $25 \%$, respectively. These outcomes demonstrate that critical load 

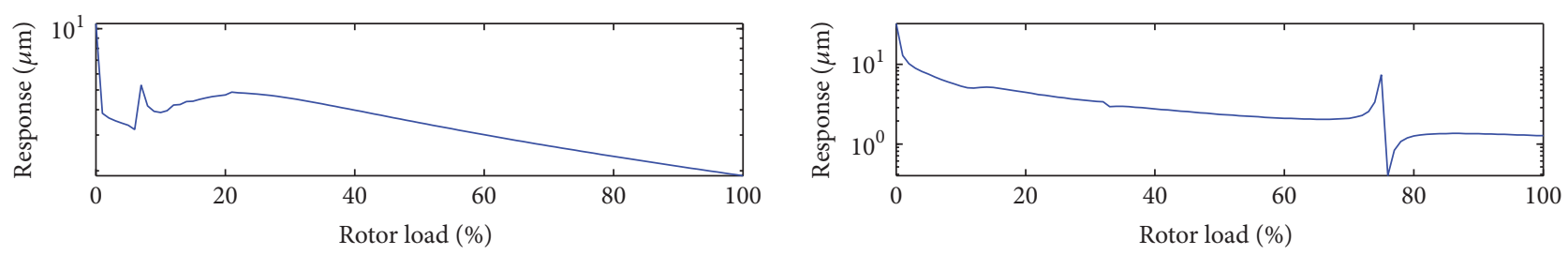

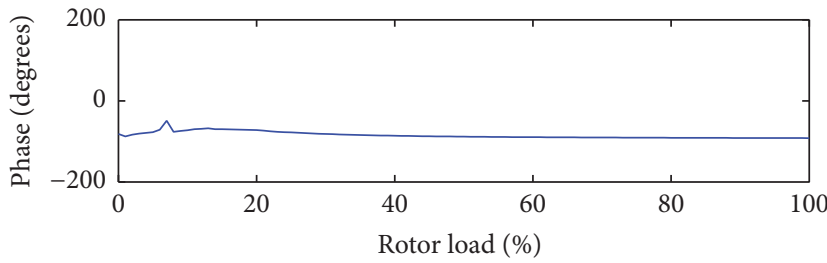

(a)

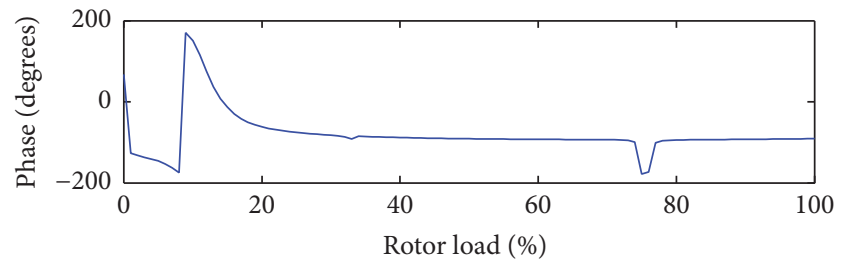

(b)
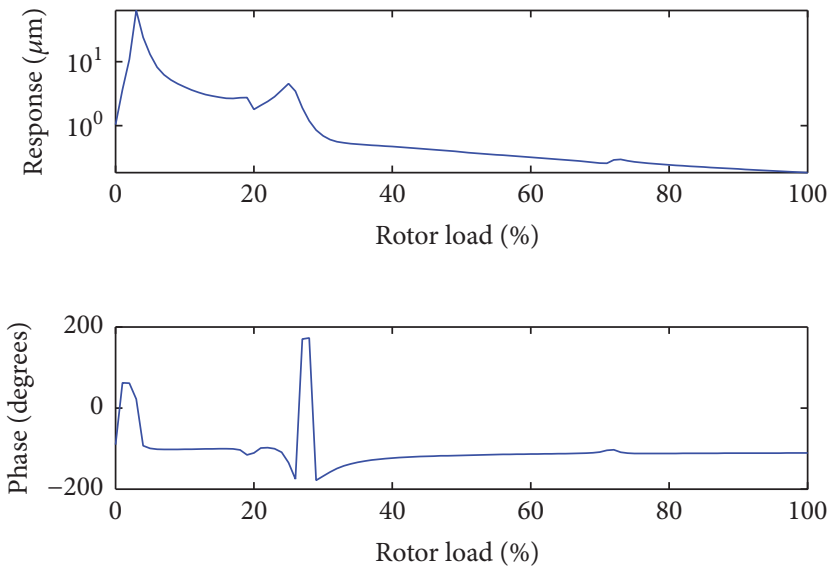

(c)

FIGURE 16: Response and phase under different workloads when three output shafts are running at the rated speed, (a) output shaft 1 running at $11131 \mathrm{r} / \mathrm{min}$; (b) output shaft 2 running at $13297 \mathrm{r} / \mathrm{min}$; (c) output shaft 3 running at $20841 \mathrm{r} / \mathrm{min}$.

phenomenon occurs in $\mathrm{O} 2$ and $\mathrm{O} 3$ when they are at the rated speed.

Our results reveal that the dynamic characteristics of the geared rotor-bearing system change as workload varies. Critical load phenomenon likely occurs as workload is adjusted in the integrally geared compressor described in this paper.

\section{Conclusions}

This study investigates the dynamic behaviors of the geared rotor-bearing system in the integrally geared compressor influenced by varying workloads. This study also examines and discusses the effects of the bearing dynamic coefficients, axial force and torque, and gear meshing stiffness on the geared rotor-bearing system under varying workloads. The critical load phenomenon of the geared rotor-bearing system is also analyzed in detail. Results are summarized as follows:

(1) The results demonstrate that the bearing dynamic coefficients, axial force and torque, and gear meshing stiffness are improved as workload increases. The bearing dynamic coefficients and gear meshing stiffness significantly affect the dynamic response of the system. By contrast, the influence of axial force and torque is not significant.

(2) Even though the rotors of the system do not have critical speed close to the rated speed under no workload conditions, the geared rotor-bearing system produces resonance with the adjusted workload, which is the critical load phenomenon. Similar to critical speed, critical load impedes the safe operation of the geared rotor-bearing system.

(3) The proposed method can be generally applied to the analysis of the critical load which should be considered in the designs of integrally geared compressors. Through the analysis of the critical load, we can adjust the rated speed to avoid the critical load failure, so as to improve the operational safety of the integrally geared compressors. 


\section{Appendix}

\section{A. Finite Rotor Element Matrices}

$$
\begin{aligned}
M_{T}^{e} & =\frac{\mu l_{e}}{420} \\
& {\left[\begin{array}{cccccccc}
156 & & & & & s y m & \\
0 & 156 & & & & & \\
0 & -22 l_{e} & 4 l_{e}^{2} & & & & \\
22 l & 0 & 0 & 4 l_{e}^{2} & & & \\
54 & 0 & 0 & 13 l_{e} & 156 & & & \\
0 & 54 & -13 l_{e} & 0 & 0 & 156 & & \\
0 & 13 l_{e} & -3 l_{e}^{2} & 0 & 0 & 22 l_{e} & 4 l_{e}^{2} & \\
-13 l_{e} & 0 & 0 & -3 l_{e}^{2} & -22 l_{e} & 0 & 0 & 4 l_{e}^{2}
\end{array}\right], }
\end{aligned}
$$$$
M_{R}^{e}=\frac{\mu_{e} r_{e}{ }^{2}}{120 l_{e}}
$$

$$
\left[\begin{array}{ccccccccc}
36 & & & & & s y m & & \\
0 & 36 & & & & & & \\
0 & -3 l_{e} & 4 l_{e}^{2} & & & & & \\
3 l_{e} & 0 & 0 & 4 l_{e}^{2} & & & & \\
-36 & 0 & 0 & -3 l_{e} & 36 & & & \\
0 & -36 l_{e} & 3 l_{e}^{2} & 0 & 0 & 36 & & \\
0 & -3 l_{e} & l_{e}^{2} & 0 & 0 & 3 l_{e} & 4 l_{e}^{2} & \\
3 l_{e} & 0 & 0 & -l_{e}^{2} & -3 l_{e} & 0 & 0 & 4 l_{e}^{2}
\end{array}\right],
$$

$$
G^{e}=\frac{2 \mu_{e} r_{e}^{2}}{120 l_{e}}
$$

$$
\begin{gathered}
\cdot\left[\begin{array}{cccccccc}
0 & & & & & \text { shew sym } \\
36 & 0 & & & & & & \\
-3 l_{e} & 0 & 0 & & & & & \\
0 & -3 l_{e} & 4 l_{e}^{2} & 0 & & & & \\
0 & 36 & -3 l_{e} & 0 & 0 & & & \\
-36 & 0 & 0 & -3 l_{e} & 36 & 0 & & \\
-3 l_{e} & 0 & 0 & l_{e}^{2} & 3 l_{e} & 0 & 0 & \\
0 & -3 l_{e} & -l_{e}^{2} & 0 & 0 & 3 l_{e} & 4 l_{e}^{2} & 0
\end{array}\right], \\
K_{B}^{e}=\frac{E_{e} I_{e}}{l_{e}^{3}}\left[\begin{array}{ccccccccc}
12 & & & & & s y m & & \\
0 & 12 & & & & & & \\
0 & -6 l_{e} & 4 l_{e}^{2} & & & & & \\
6 l_{e} & 0 & 0 & 4 l_{e}^{2} & & & & \\
-12 & 0 & 0 & -6 l_{e} & 12 & & & \\
0 & -12 & 6 l_{e} & 0 & 0 & 12 & & \\
0 & -6 l_{e} & 2 l_{e}^{2} & 0 & 0 & 6 l_{e} & 4 l_{e}^{2} & \\
6 l_{e} & 0 & 0 & 2 l_{e}^{2} & -6 l_{e} & 0 & 0 & 4 l_{e}^{2}
\end{array}\right]
\end{gathered}
$$

\section{B. Gear Meshing Stiffness Matrix}

$$
K_{g}=k_{g} \cos ^{2} \beta\left[\begin{array}{cccccccccc}
\sin ^{2} \alpha & \sin \alpha \cos \alpha & 0 & 0 & -\sin ^{2} \alpha & -\sin \alpha \cos \alpha & 0 & 0 & r_{1} \sin \alpha & r_{2} \sin \alpha \\
\sin \alpha \cos \alpha & \cos ^{2} \alpha & 0 & 0 & -\sin \alpha \cos \alpha & -\cos ^{2} \alpha & 0 & 0 & r_{1} \cos \alpha & r_{2} \cos \alpha \\
0 & 0 & 0 & 0 & 0 & 0 & 0 & 0 & 0 & 0 \\
0 & 0 & 0 & 0 & 0 & 0 & 0 & 0 & 0 & 0 \\
-\sin ^{2} \alpha & -\sin \alpha \cos \alpha & 0 & 0 & \sin ^{2} \alpha & \sin \alpha \cos \alpha & 0 & 0 & -r_{1} \sin \alpha & -r_{2} \sin \alpha \\
-\sin \alpha \cos \alpha & -\cos ^{2} \alpha & 0 & 0 & \sin \alpha \cos \alpha & \cos ^{2} \alpha & 0 & 0 & -r_{1} \cos \alpha & -r_{2} \cos \alpha \\
0 & 0 & 0 & 0 & 0 & 0 & 0 & 0 & 0 & 0 \\
0 & 0 & 0 & 0 & 0 & 0 & 0 & 0 & 0 & 0 \\
r_{1} \sin \alpha & r_{2} \sin \alpha & 0 & 0 & -r_{1} \sin \alpha & -r_{2} \sin \alpha & 0 & 0 & r_{1}^{2} & r_{1} r_{2} \\
r_{1} \cos \alpha & r_{2} \cos \alpha & 0 & 0 & -r_{1} \cos \alpha & -r_{2} \cos \alpha & 0 & 0 & r_{1} r_{2} & r_{2}^{2}
\end{array}\right] .
$$

\section{Competing Interests}

The authors declare that there is no conflict of interests regarding the publication of this paper.

\section{Acknowledgments}

The authors acknowledge the financial supported by the National Basic Research Program of China (Grant no. 
2012CB026000) and the National Science Foundation for Distinguished Young Scholars of China (Grant no. 51305020).

\section{References}

[1] S. Sutar and S. Kadam, "Analysis of geared rotors-a review," International Journal of Emerging Technology and Advanced Engineering, vol. 2, no. 10, pp. 422-424, 2012.

[2] H. D. Nelson and J. M. McVaugh, "The dynamics of rotorbearing systems using finite elements," Journal of Engineering for Industry, vol. 98, no. 2, pp. 593-600, 1976.

[3] E. S. Zorzi and H. D. Nelson, "Finite element simulation of rotor-bearing systems with internal damping," Journal of Engineering for Power, vol. 99, no. 1, pp. 71-76, 1977.

[4] E. S. Zorzi and H. D. Nelson, "Dynamics of rotor-bearing systems with axial torque-a finite element approach," Journal of Mechanical Design, vol. 102, no. 1, pp. 158-161, 1980.

[5] A. Kahraman, H. N. Ozguven, D. R. Houser, and J. J. Zakrajsek, "Dynamic analysis of geared rotors by finite elements," Journal of Mechanical Design, vol. 114, no. 3, pp. 507-514, 1992.

[6] J. S. Rao, T. N. Shiau, and J. R. Chang, "Theoretical analysis of lateral response due to torsional excitation of geared rotors," Mechanism and Machine Theory, vol. 33, no. 6, pp. 761-783, 1998.

[7] J.-S. Wu and C.-H. Chen, "Torsional vibration analysis of gearbranched systems by finite element method," Journal of Sound and Vibration, vol. 240, no. 1, pp. 159-182, 2001.

[8] S. H. Choi, J. Glienicke, D. C. Han, and K. Urlichs, "Dynamic gear loads due to coupled lateral, torsional and axial vibrations in a helical geared system," Journal of Vibration and Acoustics, vol. 121, no. 2, pp. 141-148, 1999.

[9] A. S. Lee, J. W. Ha, and D.-H. Choi, "Coupled lateral and torsional vibration characteristics of a speed increasing geared rotor-bearing system," Journal of Sound and Vibration, vol. 263, no. 4, pp. 725-742, 2003.

[10] M. Kubur, A. Kahraman, D. M. Zini, and K. Kienzle, "Dynamic analysis of a multi-shaft helical gear transmission by finite elements: Model and experiment," Journal of Vibration and Acoustics, vol. 126, no. 3, pp. 398-406, 2004.

[11] A. S. Lee and J. W. Ha, "Prediction of maximum unbalance responses of a gear-coupled two-shaft rotor-bearing system," Journal of Sound and Vibration, vol. 283, no. 3-5, pp. 507-523, 2005.

[12] C. H. Kang, W. C. Hsu, E. K. Lee, and T. N. Shiau, "Dynamic analysis of gear-rotor system with viscoelastic supports under residual shaft bow effect," Mechanism and Machine Theory, vol. 46, no. 3, pp. 264-275, 2011.

[13] Q. Han, J. Zhao, and F. Chu, "Dynamic analysis of a geared rotor system considering a slant crack on the shaft," Journal of Sound and Vibration, vol. 331, no. 26, pp. 5803-5823, 2012.

[14] Y. Zhang, Q. Wang, H. Ma, J. Huang, and C. Zhao, "Dynamic analysis of three-dimensional helical geared rotor system with geometric eccentricity," Journal of Mechanical Science and Technology, vol. 27, no. 11, pp. 3231-3242, 2013.

[15] A. Kahraman and R. Singh, "Interactions between time-varying mesh stiffness and clearance non-linearities in a geared system," Journal of Sound and Vibration, vol. 146, no. 1, pp. 135-156, 1991.

[16] A. Al-Shyyab and A. Kahraman, "Non-linear dynamic analysis of a multi-mesh gear train using multi-term harmonic balance method: period-one motions," Journal of Sound and Vibration, vol. 284, no. 1-2, pp. 151-172, 2005.
[17] C. Siyu, T. Jinyuan, L. Caiwang, and W. Qibo, "Nonlinear dynamic characteristics of geared rotor bearing systems with dynamic backlash and friction," Mechanism and Machine Theory, vol. 46, no. 4, pp. 466-478, 2011.

[18] J. J. Gao, Diagnosis and Self-healing of Mechanical Failure, Higher Education Press, Beijing, China, 2012.

[19] A. Vollan and L. Komzsik, Computational Techniques of Rotor Dynamics with the Finite Element Method, CRC Press, New York, NY, USA, 2012.

[20] Standard I.S.O. 1940-1: 2003, Mechanical Vibration-Balance Quality Requirements for Rotors in a Constant (rigid) State-Part 1: Specification and Verification of Balance Tolerances, International Organization for Standardization, Geneva, Switzerland, 2003.

[21] ISO, "Calculation of load capacity of spur and helical gearspart 1: basic principles, introduction and general influence factors," I.S.O. Standard 6336-1:2006, International Organization for Standardization, Geneva, Switzerland, 2006. 


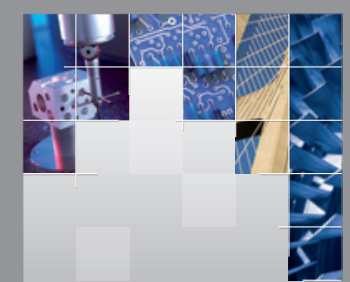

\section{Enfincering}
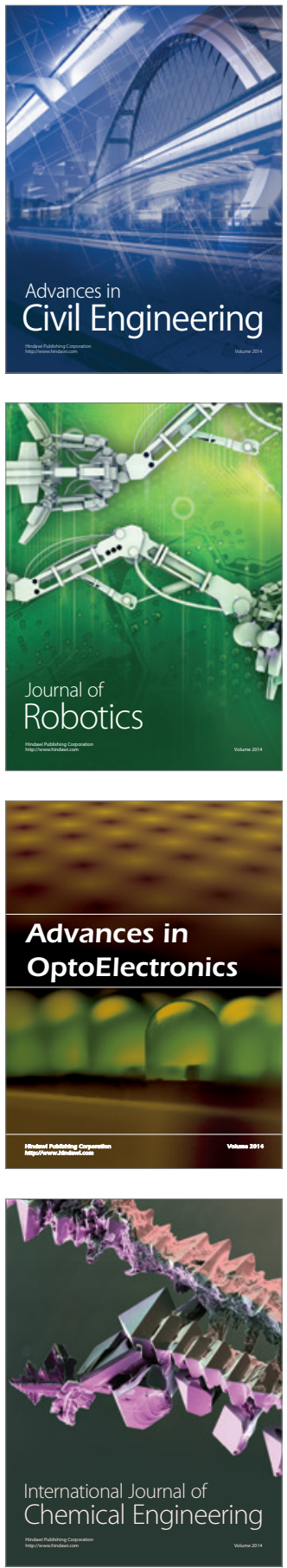

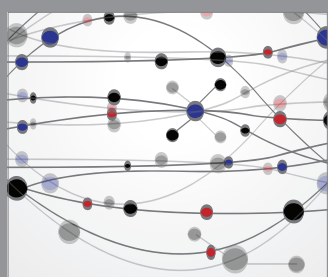

The Scientific World Journal

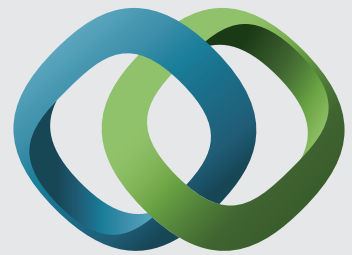

\section{Hindawi}

Submit your manuscripts at

http://www.hindawi.com
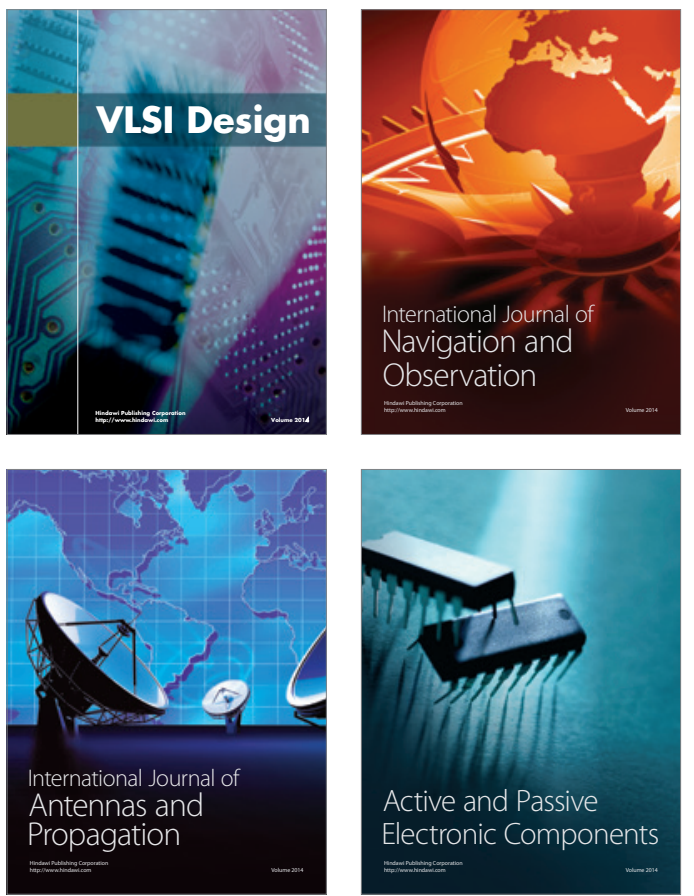
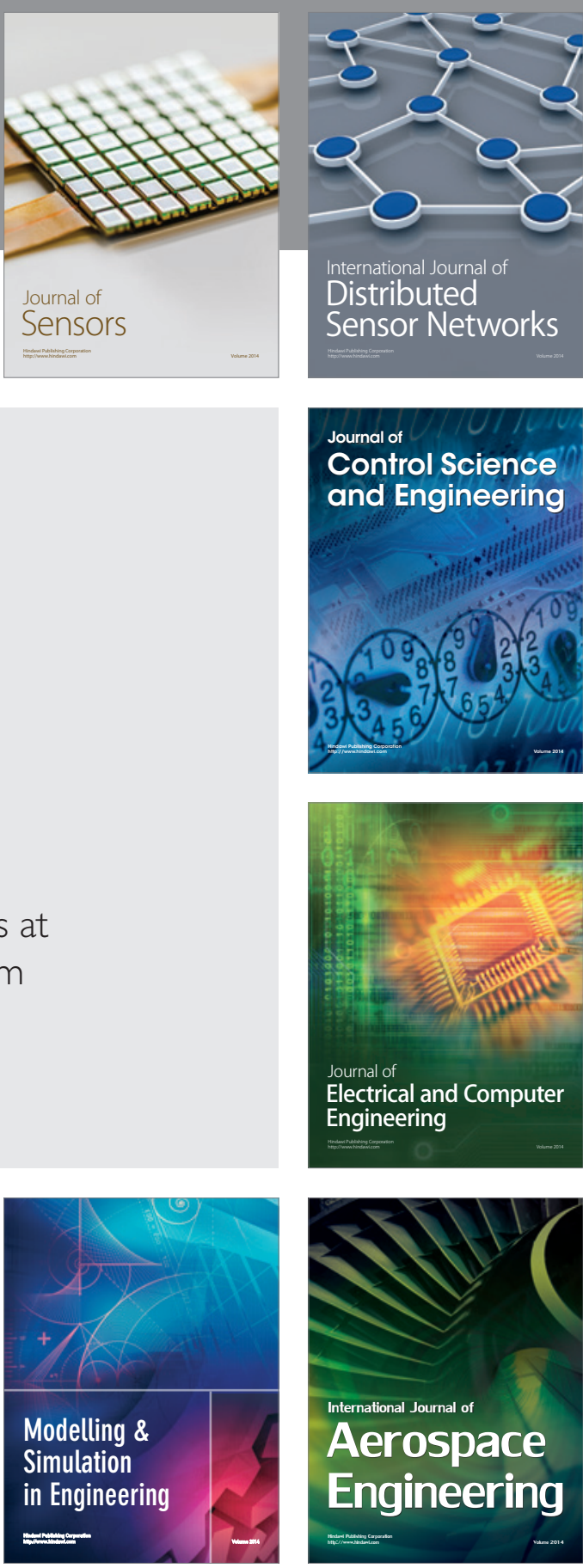

International Journal of

Distributed

Sensor Networks

Journal of

Control Science

and Engineering
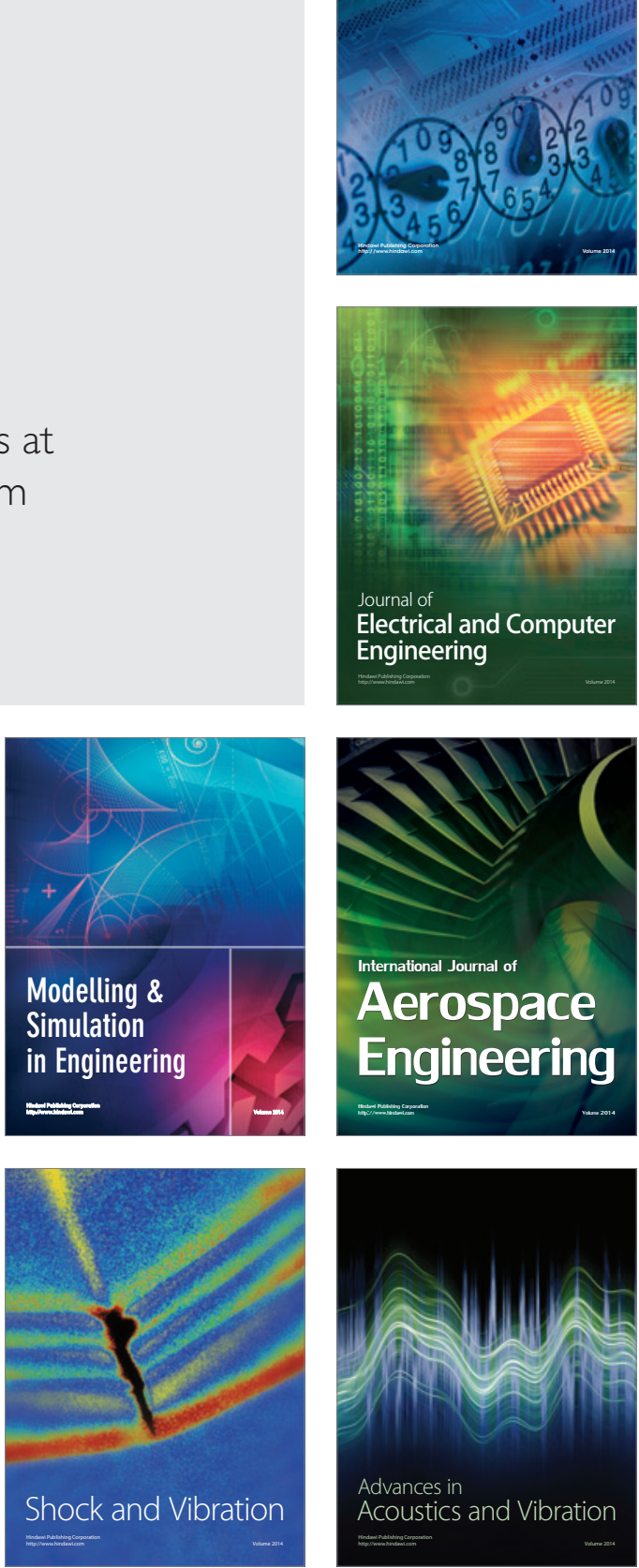